\title{
Depressogenic medications and other risk factors for depression among Polish patients with epilepsy
}

\author{
Magdalena Bosak' \\ Wojciech Turaj' \\ Dominika Dudek ${ }^{2}$ \\ Marcin Siwek ${ }^{2}$ \\ Andrzej Szczudlik' \\ 'Department of Neurology, \\ ${ }^{2}$ Department of Psychiatry, Jagiellonian \\ University Medical College, Krakow, \\ Poland
}

This article was published in the following Dove Press journal:

Neuropsychiatric Disease and Treatment

30 September 2015

Number of times this article has been viewed

Purpose: The aim of this study was to assess the prevalence of depression among patients with epilepsy and to establish the risk factors of depression in that group, with special focus on the use of potentially depressogenic medications.

Patients and methods: We studied 289 consecutive patients who visited epilepsy outpatient clinic (University Hospital of Krakow) and met inclusion criteria. All patients were screened with Beck Depression Inventory (BDI), and those with BDI score $\geq 12$ were further evaluated by a psychiatrist.

Results: Mean age of patients was 35.7 years, and mean duration of epilepsy was 14.7 years. Idiopathic generalized epilepsy was diagnosed in 63 patients $(21.8 \%)$, focal epilepsy was found in 189 subjects (65.4\%), and unclassified epilepsy was diagnosed in 37 patients (12.8\%). Frequent seizures ( $>1$ per month) were reported in 107 patients $(37.0 \%)$. Thirty-five patients $(12.1 \%)$ reported an ongoing treatment with one or more of the predefined potentially depressogenic medication ( $\beta$-blockers, combined estrogen and progestogen, corticosteroid, or flunarizine). In a group of 115 patients ( $39.8 \%$ ) who scored $\geq 12$ points in BDI, depression was finally diagnosed in 84 subjects (29.1\%) after psychiatric evaluation. Only 20 of those patients $(23.8 \%)$ were treated with antidepressant. Independent variables associated with the diagnosis of depression in the logistic regression model included frequent seizures (odds ratio $[\mathrm{OR}]=2.43[95 \%$ confidence interval, $95 \% \mathrm{CI}=1.38-4.29$ ], $P=0.002$ ), use of potentially depression-inducing medications $(\mathrm{OR}=3.33$ [95\% CI $=1.50-7.39], P=0.003)$, age $(\mathrm{OR}=1.03$ [95\% CI $=1.01-1.05]$ per year], $P=0.005$ ), and use of oxcarbazepine ( $\mathrm{OR}=2.26[95 \% \mathrm{CI}=1.04-4.9], P=0.038$ ).

Conclusion: The prevalence of depression among consecutive Polish patients with epilepsy reached $29.1 \%$. Less than quarter of them received antidepressant treatment at the moment of evaluation. Independent variables associated with depression included age, frequent seizures, and the use of oxcarbazepine or predefined depressogenic medications.

Keywords: epilepsy, depression, medication, seizures, risk factors, side effects

\section{Introduction}

Depression is more common among patients with epilepsy than in the general population. The prevalence of depression in community-based studies ranges from $13 \%$ to $36.5 \%{ }^{1,2}$ and reaches up to $54 \%$ in patients with refractory epilepsy treated in tertiary centers. ${ }^{3}$ The importance of depression among epilepsy patients is highlighted by the fact that it decreases the quality of life to a greater extent than frequent seizures themselves. ${ }^{3}$ Also, only minority of depressed patients with epilepsy are appropriately diagnosed and treated, ${ }^{4}$ which suggests that the awareness of that problem is suboptimal even in tertiary centers that should routinely screen their patients for symptoms of depression. ${ }^{5}$
Correspondence: Magdalena Bosak Department of Neurology, Jagiellonian University Medical College, Botaniczna 3, $3 \mathrm{I}-503$ Krakow, Poland

Tel +48 I2 4248600

$\mathrm{Fax}+48 \quad 124248626$

Email magdalena.bosak@uj.edu.pl 
Origin of depression among epileptic patients is most likely multifactorial. It may share some determinants with the general population (eg, unemployment, marital status), but might be also related to epilepsy-specific mechanisms such as structural or functional brain damage leading simultaneously to depression and epilepsy or, even more importantly, may result from the burden of the disease (eg, stigmatization, perceived discrimination) or may be treatment related. ${ }^{6}$

A number of possible risk factors for depression among epileptic patients was previously suggested, such as demography (older age, female sex), ${ }^{2}$ clinical factors (frequency of seizures, concomitant disorders), ${ }^{5}$ and sociodemographic factors (eg, unemployment or lower education level). ${ }^{6}$ Comorbidities such as diabetes, arterial hypertension, ischemic heart disease, hyperlipidemia, or chronic respiratory disease are associated with depression, both in the general population $^{7-9}$ and specifically in epileptic patients. ${ }^{10}$ Social and demographic issues differ in various societies and cultures. Thus, the continuing research in different countries seems justified. Only one study related to Polish epileptic patients has been published so far and it dealt exclusively with focal epilepsy. ${ }^{11}$

While the possible association between the use of some antiepileptic drugs (AEDs) and risk of depression was previously noted in regard of phenobarbital, vigabatrin, or topiramate, ${ }^{12,13}$ there are no studies showing a relationship between depression in epileptic patients and drugs other than AEDs. We have hypothesized therefore that the use of those medications may be an additional, so far unrevealed, independent risk factor for depression among patients with epilepsy.

The aims of this study were to assess the prevalence of depression among epileptic patients seen in an outpatient epilepsy center and to evaluate the risk factors for depression in those patients with the special focus on the role of depressogenic medications.

\section{Materials and methods}

\section{Patients}

Participants were recruited from consecutive patients who visited outpatient epilepsy clinic in the Department of Neurology, University Hospital in Krakow during 1 year.

Inclusion criteria were 1) diagnosis of epilepsy and its classification according to the International League Against Epilepsy, ${ }^{14,15} 2$ ) neuroimaging (magnetic resonance imaging or computed tomography, if magnetic resonance imaging was contraindicated) performed within 5 years before the inclusion to the study, and 3) informed consent of the patient.
Exclusion criteria were 1) co-occurrence of psychogenic nonepileptic seizures; 2) occurrence of tonic, atonic, clonic, or atypical absence seizures; 3) thyroid gland disease with abnormal level of thyroxine; 4) malignancies; 5) neurodegenerations or other progressive neurological disorders; 6 ) any change in type or dose of AEDs within 1 month before the potential inclusion to the study; 7) drug or alcohol abuse; 8) cognitive impairment assessed as Mini-Mental State Examination score $<24$.

The study was performed in accordance with the principles of Helsinki Declaration. The protocol of the study was approved by the bioethical committee of the Jagiellonian University of Krakow. Each subject obtained the detailed information about the goal of the study and the methods to be used and gave his/her written informed consent to participate.

\section{Methods}

The study had a cross-sectional design. After informed consent was provided by the patient, medical history was obtained and the neurological examination was performed. Data from history, examination, as well as from electroencephalography (EEG) and neuroimaging were stored in electronic database. An interview was structured and used the questionnaire that included information on age, sex, marital status, activity in their occupation, etiology and duration of epilepsy, type and frequency of seizures, ongoing treatment with $\operatorname{AED}(\mathrm{s})$, occurrence of comorbidities, ongoing use of any other medication(s), family history of epilepsy and/or depression.

Epileptic seizures and epileptic syndromes were classified according to the International Classification of Seizures ${ }^{15,16}$ and International Classification of Epilepsies and Epileptic Syndromes. ${ }^{17}$ Accordingly, seizures were classified as seizures of focal onset (focal seizures without disorders of alertness/consciousness, focal seizures with disorders of alertness/consciousness, focal seizures transformed into bilateral convulsive seizures), generalized seizures (typical absences, myoclonic, and tonic-clonic seizures), and unclassified seizures. Epileptic syndromes were classified into localization-related, generalized, or of unknown onset. Seizures were classified with the use of history, EEG/videoEEG, and neuroimaging. If all those sources were taken into consideration, the specific type of seizures was diagnosed. Otherwise, seizures were left as unclassified. Frequency of seizures was assessed with the use of seizure diaries. Data on the ongoing treatment with AEDs were collected from medical records and history provided by the patient.

The occurrence of depressive symptoms was preliminarily assessed with the Polish version of revised Beck Depression 
Inventory (BDI); it was required that the assessment would be done at least 72 hours after the last seizure (to avoid postseizure depressive symptoms). Analysis comprised depressive symptoms occurring within 1 week preceding the assessment. The first version of BDI was validated previously in Polish population, and the cut-off score of 12 points was indicated as the value suggestive for depression. ${ }^{18}$ Patients who scored at least 12 points in BDI were further consulted by the psychiatrists (DD and MS), who established the diagnosis of depression according to diagnostic criteria included in Diagnostic and Statistical Manual of Mental Disorders, 4th Edition (DSM-IV) and provided also the diagnosis of depressive syndrome according to International Classification of Diseases, 10th Edition (ICD-10).

Information on comorbidities and treatment with drugs other than AEDs, including antidepressants and previously diagnosed epilepsy, and antidepressants was collected during interview and further assessed with the medical records. We noted the presence of chronic illnesses, including arterial hypertension, ischemic heart disease, history of myocardial infarction, diabetes, hypercholesterolemia, asthma, as well as corrected hypo- or hyperthyreosis. In each patient, we recorded all medications taken for 3 months preceding the study visit, with special focus on the drugs with the potential depression-induction properties. The list of depressogenic medications was established according to the literature ${ }^{19}$ and originally included hormones (corticosteroids, estrogens, progesterone), $\beta$-blockers (mostly propranolol), calcium antagonists (flunarizine), some antiparkinsonian drugs (levodopa, amantadine), and interferons. In order to compare the impact of those medications with other drugs used by the patients, the latter ones were collated into the group of "other medications".

Family history of epilepsy and/or depression was established in interview with the patient or his/her proxies.

\section{Statistical analyses}

Qualitative variables were expressed with numbers and percentages. Quantitative variables were described with the use of a mean and standard deviation (SD). The significance of the differences between the qualitative data was analyzed using the $\chi^{2}$ test (or with Fisher exact test, where appropriate). Student's $t$-test was used to assess differences between quantitative variables.

First, univariate analysis of factors that differ between patients with and without depression was made. Then, analysis of independent factors that influenced the presence of depression (dependent variable) was performed by logistic regression modeling. An initial model was built with all the variables that differed at the level of $P<0.2$ in univariate analysis. Models were created using stepwise method: backward selection with determining criterion likelihood ratio for variables selection. A $P$-value of less than 0.05 was considered statistically significant for variables in the final model. All the analyses were performed using Statistica v10 (StatSoft Inc., Tulsa, OK, USA).

\section{Results General characteristics of the study group}

Among 467 patients who were seen in the epilepsy clinic within the period of the study, 301 subjects met the inclusion criteria and entered the study. After the assessment of depressive symptoms with BDI, 12 patients declined further assessment by the psychiatrist, and 289 patients were left for the final analysis.

Mean age of patients was 35.7 years $(\mathrm{SD}=14.9)$. Women $(n=169)$ constituted $58.5 \%$ of the studied group. One hundred sixty-three patients $(56.4 \%)$ lived alone and 111 subjects $(38.4 \%)$ were active in their profession.

Mean age at the diagnosis of epilepsy was 21.0 years $(\mathrm{SD}=15.3)$, and the mean duration of epilepsy was 14.7 years $(\mathrm{SD}=11.4)$. Idiopathic generalized epilepsy was diagnosed in 63 patients $(21.8 \%)$, focal epilepsy was found in 189 subjects $(65.4 \%)$, and unclassified epilepsy was diagnosed in 37 patients $(12.8 \%)$. One hundred and seven patients $(37.0 \%)$ had frequent seizures ( $>1$ per month), while 90 (31.1\%) were in remission (no seizure within the previous year). Monotherapy was used in 161 subjects $(55.7 \%)$. The most commonly used AEDs included valproate $(n=171,59.2 \%)$, levetiracetam $(n=70,24.2 \%)$, carbamazepine $(n=62,21.5 \%)$, and lamotrigine $(\mathrm{n}=39,13.4 \%)$.

Family history of depression was noted in 66 subjects (22.8\%), and family history of epilepsy was disclosed in 42 patients $(14.5 \%)$.

Most common comorbidities included arterial hypertension $(n=39,13.5 \%)$, hypercholesterolemia $(n=19,6.6 \%)$, ischemic heart disease $(n=11,3.8 \%)$, and diabetes $(n=7$, $2.4 \%)$. Thirty-five patients $(12.1 \%)$ reported an ongoing treatment with any of the predefined potentially depressioninducing medication ( $\beta$-blockers, $n=27$; combined estrogen and progestogen, $n=6$; corticosteroid, $n=2$; and flunarizine, $\mathrm{n}=1$; one person used $\beta$-blocker and corticosteroid, one person used $\beta$-blocker and estrogen with progestogen). Twenty-six patients (9\%) used antidepressant(s) at the time of assessment. 
Other medications used by the studied patients included angiotensin convertase inhibitors $(n=25)$, proton pump inhibitors $(n=9)$, calcium antagonists other than flunarizine $(n=30)$, oral hypoglycemics $(n=9)$, statins $(n=21)$, diuretics $(n=8)$, and inhaled $\beta_{2}$-adrenergic agonists $(n=7)$. One person used acenocoumarol, one unspecified immunosuppressant, one fibrate, and one thyroxine.

Mean score in BDI was 11.5 ( $\mathrm{SD}=9.7$ ) including 7.3 points $(\mathrm{SD}=6.5)$ in cognitive-affective subscore and 4.2 points $(\mathrm{SD}=3.8)$ in somatic subscore. One hundred fifteen patients $(39.8 \%)$ scored $\geq 12$ points in BDI and were further evaluated by the psychiatrist. After psychiatric evaluation, depression was finally diagnosed in 84 subjects (29.1\%), ie, in $73.0 \%$ of subjects with BDI $\geq 12$ points. Organic mood disorder (F06 according to ICD-10) was diagnosed in 38 patients (45.2\%), depressive episode (F32) in 27 patients $(32.1 \%)$, persistent mood disorder (F34) in 11 patients $(13.1 \%)$, and recurrent depressive disorder (F33) in 8 patients (9.5\%). Only 20 patients diagnosed with depressive symptoms $(23.8 \%)$ were treated with antidepressant(s) at the time of the psychiatric assessment.

\section{Risk factors analysis}

Tables 1 and 2 provide a detailed comparison of recorded variables between depressed and nondepressed patients with epilepsy. Univariate analysis showed that depressed patients were older, more often had a history of depression, and used antidepressants more commonly. They were older at the onset of epilepsy, and, at the time of evaluation, their disease lasted slightly longer. Patients diagnosed with depression were more commonly treated with oxcarbazepine or levetiracetam and were less likely to receive monotherapy. Frequent seizures and complex partial seizures were more often seen among depressed patients as well, while remission was less likely among them.

Patients with focal epilepsy were diagnosed with depression more often $(n=61,[32.3 \%])$ than those with generalized epilepsy $(\mathrm{n}=12[19.0 \%], P=0.045)$. Patients with frequent

Table I Comparison of demographic, clinical, and instrumental findings between depressed and nondepressed patients with epilepsy (univariate analysis)

\begin{tabular}{|c|c|c|c|}
\hline Variable & $\begin{array}{l}\text { Depressed patients } \\
(n=84)\end{array}$ & $\begin{array}{l}\text { Nondepressed patients } \\
(n=205)\end{array}$ & $\begin{array}{l}P \text {-value for the } \\
\text { difference }\end{array}$ \\
\hline Age & $41.3 \pm 15.7$ & $33.4 \pm 14.0$ & $<0.001$ \\
\hline Sex (\% of women) & $49(58.3 \%)$ & $120(58.5 \%)$ & 0.97 \\
\hline Marital status ( $\%$ of living alone) & $40(47.6 \%)$ & $123(60.0 \%)$ & 0.054 \\
\hline \multicolumn{4}{|l|}{ Education level } \\
\hline Primary school & $6(7.1 \%)$ & $23(\mathrm{I} 1.2 \%)$ & 0.33 \\
\hline Vocational school & $23(27.4 \%)$ & 38 (I8.5\%) & \\
\hline High school & $40(47.6 \%)$ & 102 (49.8\%) & \\
\hline College & $15(17.9 \%)$ & $42(20.5 \%)$ & \\
\hline Occupational activity (\% of active) & $29(34.5 \%)$ & $82(40 \%)$ & 0.38 \\
\hline History of depression & $23(27.4 \%)$ & $6(2.9 \%)$ & $<0.001$ \\
\hline Use of antidepressant(s) & $20(23.8 \%)$ & $6(2.9 \%)$ & $<0.001$ \\
\hline \multicolumn{4}{|l|}{ Comorbidities } \\
\hline Arterial hypertension & | 4 (| $6.7 \%)$ & $25(12.2 \%)$ & 0.31 \\
\hline Diabetes & $4(4.8 \%)$ & $3(1.5 \%)$ & $0.1 \mathrm{I}^{\mathrm{a}}$ \\
\hline Ischemic heart disease & $5(6.0 \%)$ & $6(2.9 \%)$ & $0.19^{a}$ \\
\hline Myocardial infarction & $2(2.4 \%)$ & $2(1.0 \%)$ & $0.33^{\mathrm{a}}$ \\
\hline Hypercholesterolemia & $9(10.7 \%)$ & $10(4.9 \%)$ & 0.07 \\
\hline Asthma & 0 & $6(2.9 \%)$ & - \\
\hline Hypothyreosis & $2(2.4 \%)$ & $2(1.0 \%)$ & $0.33^{\mathrm{a}}$ \\
\hline Hyperthyreosis & $3(3.6 \%)$ & $2(1.0 \%)$ & $0.15^{\mathrm{a}}$ \\
\hline Any comorbidity & $20(23.8 \%)$ & $35(17.1 \%)$ & 0.18 \\
\hline Use of potentially depression-inducing medication(s) & $20(23.8 \%)$ & $15(7.3 \%)$ & 0.0001 \\
\hline Use of other medication(s) ${ }^{\mathrm{a}}$ & $24(28.5 \%)$ & $38(18.5 \%)$ & 0.06 \\
\hline Family history of epilepsy & $20(23.8 \%)$ & $46(22.4 \%)$ & 0.80 \\
\hline Family history of depression & $16(19.0 \%)$ & $26(12.7 \%)$ & 0.16 \\
\hline BDI total score & $20.5 \pm 7.9$ & $7.8 \pm 7.7$ & $<0.001$ \\
\hline BDI, cognitive-affective subscore & $13.3 \pm 5.4$ & $4.9 \pm 5.1$ & $<0.001$ \\
\hline BDI, somatic subscore & $7.1 \pm 3.7$ & $3.0 \pm 1.5$ & $<0.001$ \\
\hline
\end{tabular}

Notes: a Medications other than antiepileptic drugs or depressogenic medications. Data are presented as $\mathrm{n}(\%)$ or mean \pm standard deviation.

Abbreviation: BDI, Beck Depression Inventory. 
Table 2 Comparison of epilepsy characteristics between depressed and nondepressed patients with epilepsy (univariate analysis)

\begin{tabular}{|c|c|c|c|}
\hline Variable & $\begin{array}{l}\text { Depressed patients } \\
(n=84)\end{array}$ & $\begin{array}{l}\text { Nondepressed patients } \\
(\mathrm{n}=205)\end{array}$ & $\begin{array}{l}\text { P-value for the } \\
\text { difference }\end{array}$ \\
\hline Age at onset of epilepsy & $24.9 \pm 17.2$ & $19.4 \pm 14.2$ & 0.006 \\
\hline Disease duration & $16.4 \pm 11.9$ & $|4.0 \pm|||$. & 0.10 \\
\hline \multicolumn{4}{|l|}{ Type(s) of seizures } \\
\hline Simple partial & II (I3.3\%) & $34(16.6 \%)$ & 0.46 \\
\hline Complex partial & $49(58.3 \%)$ & 80 (39.0\%) & 0.003 \\
\hline Secondary generalized & 52 (6I.9\%) & 107 (52.2\%) & 0.13 \\
\hline Absence & $9(10.7 \%)$ & $22(10.7 \%)$ & 0.99 \\
\hline Myoclonic & $5(6.0 \%)$ & $22(10.7 \%)$ & 0.20 \\
\hline Primary generalized & $13(15.5 \%)$ & 47 (22.9\%) & 0.16 \\
\hline Unclassified & $9(10.7 \%)$ & 24 (11.7\%) & 0.81 \\
\hline \multicolumn{4}{|l|}{ Treatment } \\
\hline Valproate & 43 (5।.2\%) & $128(62.4 \%)$ & 0.08 \\
\hline Carbamazepine & $15(17.9 \%)$ & 47 (22.9\%) & 0.34 \\
\hline Phenobarbital & $3(3.6 \%)$ & $7(3.4 \%)$ & 0.59 \\
\hline Primidone & $\mathrm{I}(\mathrm{I} .2 \%)$ & $5(2.4 \%)$ & 0.44 \\
\hline Phenytoin & $4(4.8 \%)$ & $4(2.0 \%)$ & 0.17 \\
\hline Clonazepam & $5(6.0 \%)$ & $4(2.0 \%)$ & 0.08 \\
\hline Lamotrigine & $13(15.5 \%)$ & $26(12.7 \%)$ & 0.53 \\
\hline Topiramate & $16(19.0 \%)$ & $22(10.7 \%)$ & 0.057 \\
\hline Vigabatrin & 0 & $2(1.0 \%)$ & - \\
\hline Levetiracetam & 27 (32.1\%) & $43(21.0 \%)$ & 0.044 \\
\hline Tiagabine & 0 & $2(1.0 \%)$ & - \\
\hline Gabapentin & $2(2.4 \%)$ & $12(5.9 \%)$ & 0.17 \\
\hline Oxcarbazepine & $17(20.2 \%)$ & $19(9.3 \%)$ & 0.01 \\
\hline Ethosuximide & 0 & $2(1.0 \%)$ & - \\
\hline Clobazam & $\mathrm{I}(\mathrm{I} .2 \%)$ & 0 & - \\
\hline \multicolumn{4}{|l|}{ Number of AEDs } \\
\hline Monotherapy & 37 (44.0\%) & $124(60.5 \%)$ & 0.011 \\
\hline 2 & $33(39.3 \%)$ & 49 (23.9\%) & 0.008 \\
\hline 3 & $13(15.5 \%)$ & 29 (I4.4\%) & 0.77 \\
\hline 4 & $\mathrm{I}(\mathrm{I} .2 \%)$ & $2(1.0 \%)$ & 0.64 \\
\hline 5 & 0 & I (0.5\%) & - \\
\hline Frequent seizures ( $>$ I per month) & $45(53.6 \%)$ & $62(30.2 \%)$ & 0.0002 \\
\hline No seizures in the previous year & $19(22.6 \%)$ & 71 (34.6\%) & 0.045 \\
\hline
\end{tabular}

Note: Data are presented as $\mathrm{n}(\%)$ or mean \pm standard deviation.

Abbreviation: AED, antiepileptic drug.

seizures $(\mathrm{n}=107)$ had depression much more commonly than patients with remission $(\mathrm{n}=90)(42.1 \%$ vs $21.1 \%$, respectively; $P=0.002$ ).

Multivariate analysis revealed several independent variables associated with the diagnosis of depression at the moment of evaluation. These included: frequent seizures (odds ratio $[\mathrm{OR}]=2.43$ ), use of potentially depression-inducing medication(s) $(\mathrm{OR}=3.33)$, age ( $\mathrm{OR}=1.03$ for each year more), and use of oxcarbazepine ( $\mathrm{OR}=2.26$ ) (Table 3 ).

Additionally, we have explored possible association between the use of depressogenic medications or oxcarbazepine and some clinical features suggestive for more severe epilepsy. Patients treated with oxcarbazepine were more often affected by frequent seizures than patients who did not use that medication ( $63.9 \%$ vs $33.2 \%$, respectively; $P=0.004)$. They were also more likely to use polytherapy
( $66.7 \%$ vs $41.1 \%$, respectively; $P=0.004$ ). Moreover, the prevalence of complex partial seizures was greater among oxcarbazepine users $(61.1 \%$ vs $42.3 \%$; $P=0.03)$.

On the other hand, patients who were exposed to depressogenic medications did not differ from their counterparts who did not use those drugs in terms of frequent seizures ( $34.3 \%$ vs $37.4 \%$, respectively; $P=0.72$ ), polytherapy ( $40.0 \%$ vs $44.9 \%$, respectively; $P=0.59$ ), or prevalence of complex partial seizures $(54.3 \%$ vs $43.3 \%$, respectively; $P=0.22$ ).

\section{Discussion}

By and large, almost $30 \%$ of epileptic patients were diagnosed with depression in this study, with independent risk factors including age, frequent seizures, use of oxcarbazepine, and use of some a priori suggested depressogenic medications. 
Table 3 Independent predictors of depression among studied patients with epilepsy (logistic regression model with backwards elimination) ${ }^{\mathrm{a}}$

\begin{tabular}{|c|c|c|c|c|}
\hline Variable & $\begin{array}{l}\text { Standard } \\
\text { error }\end{array}$ & $\begin{array}{l}\text { Wald } \\
\text { statistics }\end{array}$ & $P$-value & $\begin{array}{l}\text { Odds ratio ( } 95 \% \\
\text { confidence interval) }\end{array}$ \\
\hline Frequent seizures $^{b}$ & 0.288 & 9.55 & 0.002 & $2.43(1.38-4.29)$ \\
\hline Use of potentially depression-inducing medication(s) & 0.405 & 8.82 & 0.003 & $3.33(1.50-7.39)$ \\
\hline $\mathrm{Age}^{\mathrm{c}}$ & 0.010 & 7.99 & 0.005 & I.03 (I.0I-I.05) \\
\hline Use of oxcarbazepine & 0.394 & 4.28 & 0.038 & $2.26(1.04-4.90)$ \\
\hline
\end{tabular}

Notes: ${ }^{2}$ The following variables were removed during consecutive steps of backward elimination: monotherapy $(P=0.93)$, age at onset of epilepsy $(P=0.99)$, duration of disease $(P=0.83)$, marital status $(P=0.78)$, hypercholesterolemia $(0.62)$, complex partial seizures $(P=0.39)$, use of medications other than antiepileptic drugs or depressogenic ones $(P=0.37)$, use of levetiracetam $(P=0.30)$, use of valproic acid $(P=0.24)$, any comorbidity $(P=0.10)$, use of clonazepam $(P=0.06)$, and use of topiramate $(P=0.06)$. ${ }^{b} S$ eizures more frequent than I per month. 'Odds ratio for the difference of I year.

Estimates of depression prevalence and incidence among patients with epilepsy vary greatly in relation to the setting (tertiary centers vs community-based samples), type of epilepsy (all types vs generalized vs focal), and type of epileptic syndrome (eg, juvenile myoclonic epilepsy vs temporal lobe epilepsy). Prevalence of depression may also differ in various countries with some inherent factors playing their own role (eg, level of unemployment, availability of social services, model of the family, and its rapid change perceived currently in Poland). It seems worth noting that the percentage of patients with depression revealed in this study (29.1\%) is actually very similar to the most recent estimates reported in cohort studies among patients with various types of epilepsy $(22.3 \%-29.3 \%){ }^{20-23}$ While it may be argued that community-based studies provide more accurate estimates of the prevalence of depression, recent systematic review and meta-analysis of such studies ${ }^{24}$ brought very similar findings (an overall prevalence of active depression reaching 23.1\%, with $95 \%$ confidence interval of $20.6 \%-28.3 \%$ ), which may suggest that the cohort studies provide reliable data.

This study did not include a control group of healthy subjects as it focused on the risk factors of depression among epileptic patients. It is worth noting, however, that the most recent population-based study (EZOP-Poland), performed in accordance with World Health Organization recommendations, revealed that $3.0 \%$ (95\% confidence interval: $2.7 \%-3.3 \%$ ) of Polish general population (aged 18-64) is affected with depression and that a further $0.6 \%$ (95\% confidence interval: $0.5 \%-0.8 \%$ ) suffers from dysthymia. ${ }^{25}$

More advanced age was an independent but weak ( $\mathrm{OR}=1.03$ per each additional year of age) risk factor for depression among studied patients, and this corroborated previous findings on that topic., ${ }^{2,26}$ This association might stem from the accumulation of all detrimental contributors (eg, somatic disorders and perceived disability) with age, as well as from the sociodemographic factors (loneliness, lack of support, hopelessness).
Frequent seizures (ie, occurring more often than once per month) independently increased the risk of depression in this study ( $\mathrm{OR}=2.43$ ), which is in agreement with numerous previous studies, including several population-based studies $^{6,27}$ and studies in patients with idiopathic generalized epilepsy, ${ }^{28}$ juvenile myoclonic epilepsy, ${ }^{29}$ or various types of epilepsy. ${ }^{5}$ Frequent seizures may adversely affect mood through a variety of mechanisms, including psychosocial factors (eg, unemployment, difficulty to maintain stable relationships, stigmatization), iatrogenic influence of polytherapy (including increased probability of drug interactions and side effects), and some biological determinants for both seizures and depression. It is also possible that this association is bidirectional, ie, that the depressed mood affects the efficacy of treatment (eg, due to lesser compliance or unwillingness to pursue more challenging modifications of lifestyle, diet, etc).

The apparent association between the use of oxcarbazepine and depressive symptoms among epileptic patients might be viewed as an unexpected finding, given the use of oxcarbazepine and its closely related compound - carbamazepine - in the management of bipolar disorder. According to our findings, however, patients who used oxcarbazepine were more likely to exhibit some features suggestive for more severe epilepsy. They were more often treated with polytherapy, had frequent seizures more commonly, and were more likely to experience complex partial seizures. Furthermore, patients treated with oxcarbazepine were more frequently living alone ( $70 \%$ vs $56 \%$ ), which is another factor suggested by some authors as associated with greater risk of depression among epileptic patients. ${ }^{30}$ Thus, we believe that the use of oxcarbazepine reflects the features of more severe epilepsy (leading itself to a greater prevalence of depression) rather than the impact of medication on their mood.

On the other hand, the possible link between the severity of epilepsy and the use of depressogenic drugs is highly unlikely. The prevalence of clinical features consistent with 
more severe epilepsy (ie, frequent seizures, complex partial seizures, or polytherapy) was similar between patients who used or did not use depressogenic medications.

The key finding of our study was an association between heterogeneous group of potentially depression-inducing medications and depression among patients with epilepsy. While a number of such medications can be listed, we have chosen four classes or individual medications that have been used by our patients. The number of patients who used specific medications potentially inducing depression was small in this study; thus, we could only collate data regarding all those drugs in one group. As $\beta$-blockers were predominant in that group of medications $(27 / 35)$, we performed additional post hoc analysis that used $\beta$-blockers only and it produced the borderline significance in logistic regression model $(P=0.055)$, suggesting that either the sample was too small to provide definite evidence or that some other drugs also contributed to the overall finding.

The depressogenic action of $\beta$-blockers is most probably related to the decrease of noradrenergic activity of the brain, ${ }^{31}$ or alternatively, to the affinity to $5 \mathrm{HT} 1 \mathrm{~A}$ receptors. Association between $\beta$-blockers and depression is suggested by some studies ${ }^{32}$ but refuted in others; ${ }^{33}$ it was shown, however, that the use of nonselective, highly lipophilic $\beta$-blockers (eg, propranolol) significantly increases the risk of depressive symptoms. ${ }^{31}$

Female sex hormones can affect mood by the lowering of serotonin concentration secondary to the increased monoamine oxidase activity induced by progesterone or by the estrogen-induced loss of pyridoxine, resulting in the decrease of levels of brain serotonin. ${ }^{34}$

Depression-inducing properties of flunarizine were ascribed either to the dopaminergic blockade or to the calcium antagonism. ${ }^{35,36}$ Corticosteroids have been linked to mood disturbances for decades due to their impact on cortisol levels. ${ }^{37}$

While the mechanisms are probably too complex to be reliably discerned, it seems prudent not to change the management strategy in epileptic patients who do not exhibit any mood disturbance. At the same time, the recognition of depressive symptoms in patients with epilepsy should prompt comprehensive evaluation which ought to include assessment of depressogenic medications, not necessarily associated with nervous system at first glance.

An interesting but controversial link between depression and epilepsy stems from the phenomenon of "forced normalization", defined as an acute or subacute onset of neuropsychiatric disturbances, including depression, associated with remission of clinical seizures and disappearance of epileptiform activity in EEG. ${ }^{38}$ It is hypothesized that the regulatory response to frequent seizures leads to altered balance of GABA-ergic and glutamatergic activity in favor of inhibition. Such a change might simultaneously produce some neuropsychiatric disturbances (eg, depression). Interestingly, the use of some antiepileptic drugs (eg, levetiracetam) was reported as the triggering factor for the forced normalization. ${ }^{39}$ The design of the current study precluded the longitudinal evaluation of the sequence of events required to diagnose this phenomenon, but it seems reasonable to consider its assessment in future studies.

The authors acknowledge some limitations of the study. The sample size, although relatively small, is actually comparable to most previous studies with similar design. While it was not a community-based study, it should be stressed that the vast majority of epileptic patients in Poland are managed in epilepsy clinics rather than by general practitioners. Also, formal psychiatric evaluation was performed only in those who scored $\geq 12$ points in BDI, which may seem to underestimate the absolute number of patients with depression. On the other hand, this approach resembles closely the everyday clinical practice in which patients are referred to the psychiatrist after the depressive symptoms are revealed during the history-taking or after the use of dedicated questionnaires, as was the case in our study. The detailed discussion of specific subtypes of depressive disorders within the cohort of patients reported here was published elsewhere. ${ }^{40}$

While some independent risk factors for epilepsy had been already precisely described, it seems worth focusing on the potential depression-inducing medications as the possibly avoidable source of depressive symptoms among epileptic patients. Therefore, we are currently preparing the study which would focus on this topic more specifically, hoping to recruit enough patients to assess the relative involvement of specific types of medications. Nevertheless, the evidence should be considered provisional and should not guide any treatment decisions at the time.

\section{Conclusion}

The prevalence of depression in the cross sectional sample of consecutive Polish patients with epilepsy reached 29.1\%. Independent variables associated with depression among studied patients included age, frequent seizures, the use of oxcarbazepine, and treatment with some depression-inducing medications ( $\beta$-blockers, corticosteroids, estrogen with progestogen and flunarizine). 


\section{Acknowledgment}

The National Leading Research Center funded publishing of the manuscript.

\section{Disclosure}

The authors report no conflicts of interest in this work.

\section{References}

1. Ettinger A, Reed M, Cramer J. Epilepsy impact project group: depression and comorbidity in community-based patients with epilepsy or asthma. Neurology. 2004;63:1008-1014.

2. Fuller-Thomson E, Brennenstuhl S. The association between depression and epilepsy in a nationally representative sample. Epilepsia. 2009;50: 1051-1058.

3. Boylan LS, Flint LA, Labovitz DL. Depression but not seizure frequency predicts quality of in treatment-resistant epilepsy. Neurology. 2004; 62:258-261.

4. Kanner AM, Palac S. Depression in epilepsy: a common but often unrecognized comorbid malady. Epilepsy Behav. 2000;1:37-51.

5. Dias M, Bateman LM, Farias ST, et al. Depression in epilepsy is associated with lack of seizure control. Epilepsy Behav. 2010;19: 445-447.

6. Mensah SA, Beavis JM, Thapar AK, Kerr M. The presence and clinical implications of depression in a community population of adults with epilepsy. Epilepsy Behav. 2006;8:213-219.

7. Penninx BW, Milaneschi Y, Lamers F, Vogelzangs N. Understanding the somatic consequences of depression: biological mechanisms and the role of depression symptom profile. BMC Med. 2013; 11:129.

8. Pietrzyk E, Gorczyca-Michta I, Michta K, Nowakowska M, Wożakowska-Kapłon B. Depresja u chorych po pomostowaniu aortalnowieńcowym [Depression in patients after coronary artery bypass grafting]. Psychiatr Pol. 2014;48:987-996. Polish.

9. Kalka D. Poczucie jakości życia a objawy depresji i sposoby radzenia sobie ze stresem u osób z cukrzycą typu 2 - doniesienie wstępne [The quality of life, symptoms of depression and coping with stress among individuals with type 2 diabetes - preliminary study]. Psychiatr Pol. 2014;48:931-940. Polish.

10. Kui C, Yingfu P, Chenling X, Wenqing W, Xiuhua L, Di S. What are the predictors of major depression in adult patients with epilepsy. Epileptic Disord. 2014;16:74-79.

11. Grabowska-Grzyb A, Jedrzejczak J, Nagańska E, Fiszer U. Risk factors for depression in patients with epilepsy. Epilepsy Behav. 2006; 8:411-417.

12. Mula M, Sander JW. Negative effects of antiepileptic drugs on mood in patients with epilepsy. Drug Saf. 2007;30:555-567.

13. Celano CM, Freudenreich O, Fernandez-Robles C, Stern TA, Caro MA, Huffman JC. Depressogenic effects of medications: a review. Dialogues Clin Neurosci. 2011;13:109-125.

14. Commission on classification and terminology of International League Against Epilepsy. Proposal for revised classification of epilepsies and epileptic syndromes. Epilepsia. 1989;30:389-399.

15. Guidelines for epidemiologic studies on epilepsy commission on epidemiology and prognosis, International League Against Epilepsy. Epilepsia. 1993;34:592-596.

16. Proposal for revised clinical and electrographic classification of epileptic seizures from the commission on classification and terminology of the International League Against Epilepsy. Epilepsia. 1981;22: 289-501.

17. Berg AT, Berkovic SF, Brodie MJ, et al. Revised terminology and concepts for organization of seizures and epilepsies: report of the ILAE commission on classification and terminology, 2005-2009. Epilepsia. 2010;51:676-685.
18. Parnowski T, Jernajczyk W. Skala Depresji Becka do oceny nastroju u osób zdrowych i u pacjentów z zaburzeniami afektywnymi [Beck's depression inventory in the rating of mood in normal subjects and in patients with affective disturbances]. Psychiatr Pol. 1977;11:417-421. Polish.

19. Patten SB, Barbui C. Drug-induced depression: a systematic review to inform clinical practice. Psychother Psychosom. 2004;73:207-215.

20. Seminario NA, Farias ST, Jorgensen J, Bourgeois JA, Seyal M. Determination of prevalence of depression in an epilepsy clinic using a brief DSMIV-based self-report questionnaire. Epilepsy Behav. 2009;15:362-366.

21. Zhao T, Sun MY, Yu PM, et al. Evaluation of clinical aspects and quality of life as risk factors for depression in patients with epilepsy. Seizure. 2012;21:367-370

22. de Oliveira GN, Lessa JM, Gonçalves AP, Portela EJ, Sander JW, Teixeira AL. Screening for depression in people with epilepsy: comparative study among Neurological Disorders Depression Inventory for Epilepsy (NDDI-E), Hospital Anxiety and Depression Scale Depression Subscale (HADS-D), and Beck Depression Inventory (BDI). Epilepsy Behav. 2014;34:50-54.

23. Zis P, Yfanti P, Siatouni A, Tavernarakis A, Gatzonis S. Determinants of depression among patients with epilepsy in Athens, Greece. Epilepsy Behav. 2014;33:106-109.

24. Fiest KM, Dykeman J, Patten SB, et al. Depression in epilepsy: a systematic review and meta-analysis. Neurology. 2013;80:590-599.

25. Kantorska-Janiec M. Rozpowszechnienie depresji. In: Moskalewicz J, Kiejna A, Wojtyniak B, editors. Kondycja psychiczna mieszkańców Polski: raport $\mathrm{z}$ badań "Epidemiologia zaburzeń psychiatrycznych i dostęp do psychiatrycznej opieki zdrowotnej - EZOP Polska". [Mental health of Polish citizens. A report from "Epidemiology of mental disorders and access to mental health care. EZOP-Poland" study.] Warszawa, Poland: Instytut Psychiatrii i Neurologii. 2012:185-194.

26. Peng W-F, Ding J, Li X, Mao L-Y, Wang X. Clinical risk factors for depressive symptoms in patients with epilepsy. Acta Neurol Scand. 2014;129:343-349.

27. Kobau R, Gilliam F, Thurman DJ. Prevalence of self-reported epilepsy or seizure disorder and its associations with self-reported depression and anxiety: results from the 2004 Healthstyles Survey. Epilepsia. 2006; 47:1915-1921.

28. Akanuma N, Hara E, Adachi N. Psychiatric comorbidity in adult patients with idiopathic generalized epilepsy. Epilepsy Behav. 2008;13: $248-251$.

29. de Araujo Filho GM, Pascalicchio TF, Sousa PS. Psychiatric disorders in juvenile myoclonic epilepsy: a controlled study of 100 patients. Epilepsy Behav. 2007;10:437-441.

30. Thompson AW, Miller JW, Katon W, Chaytor N, Ciechanowski P. Sociodemographic and clinical factors associated with depression in epilepsy. Epilepsy Behav. 2009;14:655-660.

31. Luijendijk HJ, van den Berg JF, Hofman A, Tiemeier H, Stricker BH. $\beta$-blockers and the risk of incident depression in the elderly. J Clin Psychopharmacol. 2011;31:45-50.

32. Patten SB. Propranolol and depression: evidence from the antihypertensive trials. Can J Psychiatry. 1990;35:257-259.

33. Ko DT, Hebert PR, Coffey CS, Sedrakyan A, Curtis JP, Krumholz HM. $\beta$-blocker therapy and symptoms of depression, fatigue, and sexual dysfunction. JAMA. 2002;288:351-357.

34. Oinonen KA, Mazmanian D. To what extent do oral contraceptives influence mood and affect? J Affect Disord. 2002;70:229-240.

35. Capellà D, Laporte JR, Castel JM, Tristán C, Cos A, Morales-Olivas FJ. Parkinsonism, tremor, and depression induced by cinnarizine and flunarizine. BMJ. 1988;297:722-723.

36. Micheli FE, Pardal MM, Giannaula R, et al. Movement disorders and depression due to flunarizine and cinnarizine. Mov Disord. 1989;4: 139-146.

37. Bolanos SH, Khan DA, Hanczyc M, Bauer MS, Dhanani N, Brown ES. Assessment of mood states in patients receiving long-term corticosteroid therapy and in controls with patient-rated and clinician-rated scales. Ann Allergy Asthma Immunol. 2004;92:500-505. 
38. Krishnamoorthy ES, Trimble MR, Sander JW, Kannerc AM. Controversies in epilepsy and behavior: forced normalization at the interface between epilepsy and psychiatry. Epilepsy Behav. 2002;3:303-308.

39. Anzellotti F, Franciotti R, Zhuzhuni H, D’Amico A, Thomas A, Onofrj M. Nonepileptic seizures under levetiracetam therapy: a case report of forced normalization process. Neuropsychiatr Dis Treat. 2014;10:959-964.
40. Bosak M, Dudek D, Siwek M, Szczudlik A. Subtypes of interictal depressive disorders according to ICD-10 in patients with epilepsy. Neurol Neurochir Pol. 2015;49:90-94.

\section{Publish your work in this journal}

Neuropsychiatric Disease and Treatment is an international, peerreviewed journal of clinical therapeutics and pharmacology focusing on concise rapid reporting of clinical or pre-clinical studies on a range of neuropsychiatric and neurological disorders. This journal is indexed on PubMed Central, the 'PsycINFO' database and CAS, and is the official journal of The International Neuropsychiatric Association (INA). The manuscript management system is completely online and includes a very quick and fair peer-review system, which is all easy to use. Visit http://www.dovepress.com/testimonials.php to read real quotes from published authors.

Submit your manuscript here: http://www.dovepress.com/neuropsychiatric-disease-and-treatment-journal 